\title{
Productivity improvement of the water meter's body manufacturing process
}

\author{
Jolanta B. Krolczyk ${ }^{1 *}$, Stanislaw Legutko², and Agnieszka Soberska ${ }^{2}$ \\ ${ }^{1}$ Opole University of Technology, Faculty of Mechanical Engineering, 76 Proszkowska Street, 45-758 \\ Opole, Poland \\ ${ }^{2}$ Poznan University of Technology, Faculty of Mechanical Engineering and Management, 3 Piotrowo \\ Street, 60-965 Poznan, Poland
}

\begin{abstract}
In the paper, the water meter's body manufacturing process, in the aspect of its productivity improvement was analyzed. The analysis was focused on the identification of the fundamental problems of manufacturing company, related to the productivity, and subsequently on the ideas of their elimination (alternatively limitation). The paper was focused on the analysis of problems influencing productivity and ideas of their elimination. The experimental research results related to the productivity, generation of production shortages and also the dimensional deviations of the water meter's body were also presented.
\end{abstract}

\section{Introduction}

Most contemporary manufacturers are making efforts, the essence of which is the determination of the ways of acquisition or maintenance of their position in the competitive environment [1]. More efficiently process that the greater will be the companies' productivity [2]. The main fault of companies is a too high net cost of product due defects [3]. The defects of manufactured products can be caused by the inappropriately selected technological input parameters, condition and properties of a machine, as well as the process dynamics [4-6]. Several techniques have been used successfully aiming at reducing the manufacturing defects $[6,7]$. With increased dimension accuracy of the products, the methods of defects analysis of machine components are ever demanding $[8,9]$.

Quality is an important thing in analysing the aspect of competitiveness, productivity and costs [1]. Increase of productivity can be achieved by improvement of the operational activity and increase of the employees commitment [10]. Operational activity can be improved by increasing the expenses on investigations and development works. More expenses on R\&D will contribute to identification of new products and new applications for the existing ones and new methods of manufacturing them [11].

The major purpose of the present work is an analysis of the process of production of water meter body in a factory of fittings in order to increase productivity. The scope of the work includes identification of the major problems of the enterprise influencing the

\footnotetext{
${ }^{*}$ Corresponding author: j.krolczyk@po.opole.pl
} 
productivity of the water meter body manufacturing. Concept of eliminating or reducing the problems is presented also in this paper.

\section{Materials and methods}

The production process analysis has been performed in an enterprise located in Poland producing fittings and devices for liquid propane-butane gas, as well as for technical gases. The factory cooperates with companies of all over the world, exporting over $50 \%$ of its production to the countries of Europe and USA to the automotive branch (40\%), building market (30\%), installation (15\%) and gas markets (15\%). The main assortment offered by the companies includes: rings of gear box synchronizer; machined water meter bodies (Figure 1); gas bottle valves; etc. Since 2010, the strategic product manufactured by the enterprise is the water meter body (Figure 1) the sales of which is growing each year.

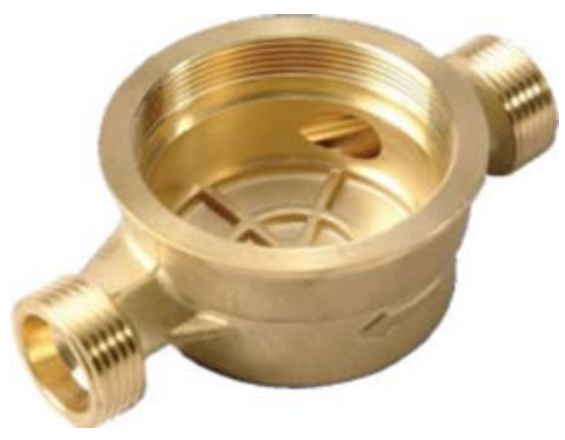

Fig. 1. Water meter body.

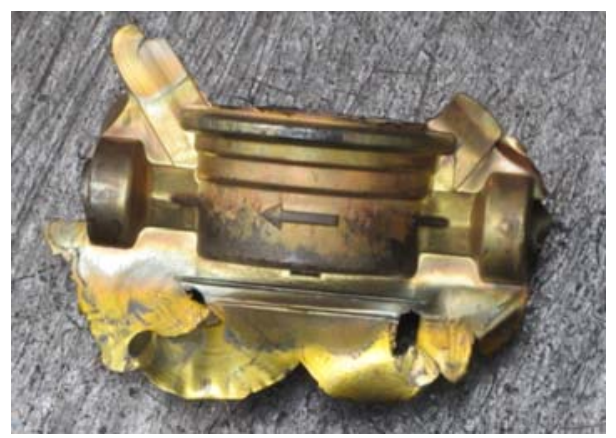

Fig. 2. A forging with flash.

The constructional elements of the water meter are made of brass, MO 58, stainless steel and plastics: PP, PPO, EPDM, PPA. The technological process includes modification of the form, chemical and physical properties of the material being processed. The blank in the process is an extruded brass rod with the diameter of $40 \mathrm{~mm}$ provided by an external supplier. The rod is cut with a transverse saw, ADIGE CM 601, into sections of $46 \mathrm{~mm}$ length and mass of $0.485 \mathrm{~kg}$ with the tolerance up to $0.005 \mathrm{~kg}$. Disk formed blanks are cut out at intervals of four seconds. The next stage is transport of the blanks from the store to the forging plant. The process of forging is performed on the crank press, ROVETTA PRESSE FO 300. In one 8 hour shift, an employee should make 3478 parts of forgings. The specific time of execution of one part is 6.1 seconds while heating takes 6 seconds. Crank presses are intended for hot forging. In the heater, the blank is heated up to the temperature of about $720^{\circ} \mathrm{C}-740^{\circ} \mathrm{C}$. Improperly heated material is shifted by the feeder to a selected chest. Hot semi product is taken by the manipulator from the discharge channel and put into the die. Next, the process of forging follows resulting in forgings (Figure 2). The next operation is trimming which is performed on the eccentric press, KD 2128 with the force of 63 tons. The next process is cleaning, also referred to as shot peening. The operation is performed on a strip cleaner, OWT-400. It consists in covering the forgings with shot and takes about an hour. The last stage is "final finishing" on a transfer machine tool, GNUTTI. During a shift, the operator should make 2000 parts of the water meter bodies. The company has two such machines working in parallel. After machining, the bodies are dried to get rid of the coolant remaining after machining and to remove chips. Next, assembling is executed. The last auxiliary procedures of the production process include actions related to: preparation of production, transport, quality control and storing. 


\section{Problems limiting productivity}

Productivity is a serious problem of the company because there is high demand of the water meter bodies, the percentage of defective parts is relatively high and production capability is limited. The survey performed in the company shows that over 9500 defective parts were made in August 2014). The percentage of body water meter manufacturing defects comes from metal forming (55\%) and machining (45\%). This means that 114000 defective parts can be made in a year; with the annual production determined at the level of 1200000 , this will generate as much as $9.5 \%$ defective parts in the whole production.

In connection with the above, the basic factor increasing productivity would be significant reduction of the number of defects in the products. It has been found that product defects appearing during other stages of processing result from incorrect forging. When the material does not flow correctly during the process of forging, fractures may occur on the collar, as well as too thin or not full fillings on the collar (Figure 3) or on the thread, material delaminations, air cavities on the thread (Figure 4) or in the inlet.

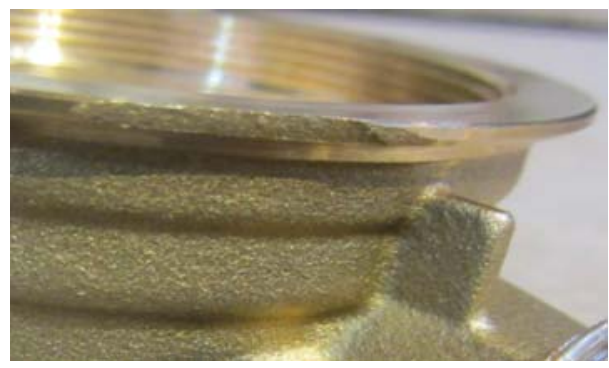

Fig. 3. Defects of machined surfaces due to improper material flow: on the collar.

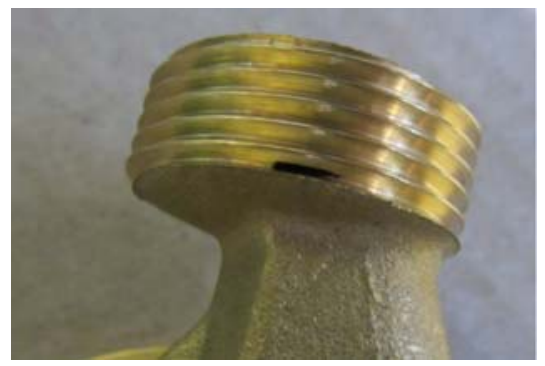

Fig. 4. Defects as a result of improper flow of material: air cavity

It has been determined during the investigation that machining causes more oscillations in the bottom thickness values for various tested bodies as compared to the proves of forging.

Defective products can also be made on the assembling stand due to employee's inattention, e.g. improper position of the plate, too weak clamping of the plate by the press, fixing of cracked strainers or deflection of the collar. Productivity problems include not only generation of many defective products, but also organization of the working stands. Much time intended for machining is lost for unplanned idling, for example pouring oil, water, cleaning jammed water pipes enabling chips removal, unplanned tool exchange, cleaning, drum failures.

There are also problems with material transport. There are two fork lift operators in a shift. One of them works in the store, the other in the production hall and the forging plant. They must ensure raw material circulation not only for the water meter body, but also for many other products. Additionally, they have to carry out waste and ready made products. 15 minutes of waiting for material on one GNUTTI machine tool results in the drop of productivity by about 64 parts in a shift. Figure 5 shows a diagram presenting the problems influencing the productivity of the water meter body manufacturing. The most important problems are marked with red.

\section{Proposals to increase productivity}

Recently, the company has bought a modern, twice as productive hydraulic press, MECOL PRESS ME 250, in order to increase the rate and, consequently, productivity of forging 
while maintaining high quality level. The new press also makes it possible to eliminate trimming of the flash, which will save time and accelerate the whole process. The forgings of the new press are more accurate and more repeatable. The high quality of the forgings influences improvement of the further processes.

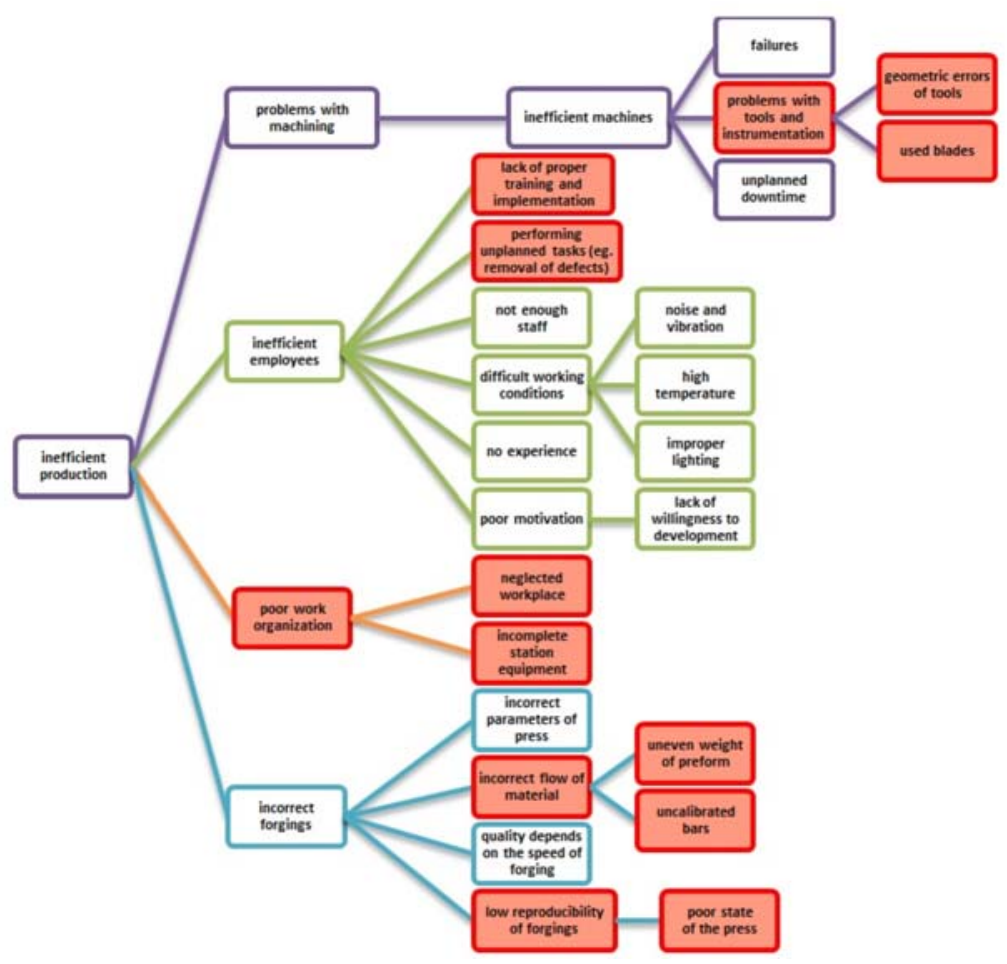

Fig. 5. The problems affecting the production capacity of the body water meter.

The water meter body is a strategic product and that is why actions involved in the production of it have priority. Earlier observation suggests that the bottleneck is caused by the machining process. In order to eliminate unplanned idling on the machines (e.g. waiting for the material, seeking the fork lift operator) one can provide employees in short wave radio or a pager to accelerate the transfer of information from the machine concerning the necessity of transporting the chests with the material.

Another solution to rationalize the machine tool operator's work is to provide him with exchangeable tools. There are several tools working on the machine simultaneously; they get worn and, consequently blunt. In order to analyse the influence of the machine idling time, investigation concerning the number of machined bodies in a period of time has been performed (Figure 6).

The data show that the least number of parts has been machined in the time period of 8.00 a.m to 10.00 a.m. This is due to the machine idling from 8.38 till 9.26 caused by the necessity of regeneration of the cutting tool edges. For this purpose, the operator disassembles the blunt tool from the machine, carries it to the tool-room, regenerates it on a grinding machine and finally, with the help of the foreman, fixes the sharpened tool in the machine. The whole operation takes a lot of time while the machine is not functioning. In order to minimize idling times, the machine could be provided with a set of spare tools, so that the tool can just be replaced during idling, which will take about 21 minutes instead of 
48 minutes. A responsible and competent person should also be selected, e.g. a foreman whose task will be to make sure that the spare tools are always sharpened and adequately marked to avoid problems with identification of the tool intended for the given operation.

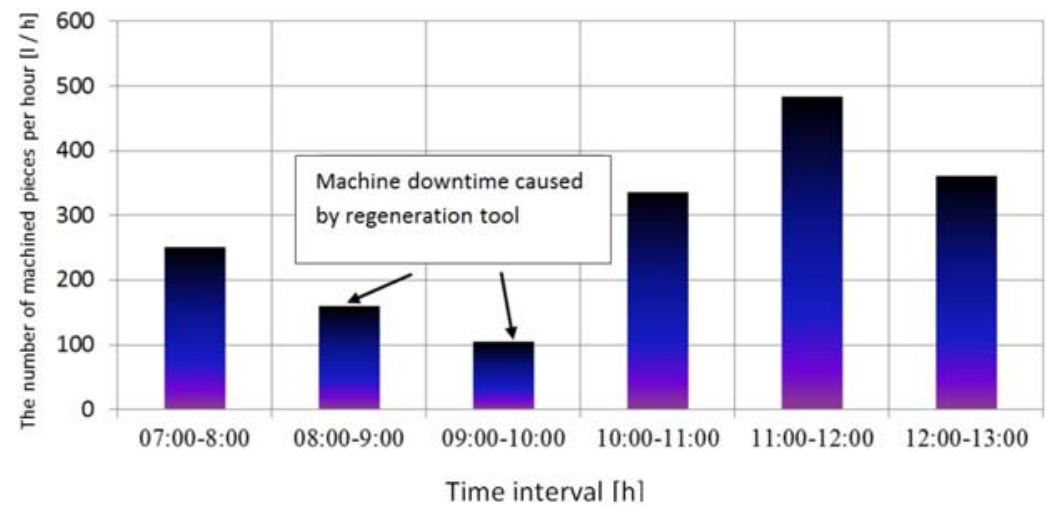

Fig. 6. Number of machined bodies for an hour in the time period from 7:00 to 13:00.

Insufficient training of the employees and their poor experience are also serious trouble. Employees often unwillingly generate defective parts. They cannot check quality in the correct way, due to which defective parts often pass through the whole production process. Additional training of the production employees should be performed.

One of the major causes of defects in the machined bodies (e.g. burrs on the edges, incorrectly machined thread) is excessive wear (blunt edges) of the cutting tools. In some cases, the phenomenon of wear is not identified by the operator at the right time and, consequently, the machines (often many parts) with a blunt edge. In order to reduce the influence of the cutting edge wear on generation of defective parts, one of the methods of the edge condition monitoring could be adopted. Cutting wedge condition can be realized by the following methods: direct ones or indirect ones. From among the indirect methods, the one practically applied is the one based on the measurement of the components of the total force. In order to reduce the number of defective part resulting from blunting of the cutting tool edge, purchase of a stand for supervising the edge condition has been suggested. This involves significant costs of force gauges, amplifiers, software for the analysis and supervision of the edges, as well as modification of the machine tool. Considering that almost half of the defective parts result from the problems of machining, the investment will be paid back in a short time.

Another problem influencing the occurrence of defective parts are dimension errors (mostly on the internal surfaces) which appear after machining. One of the reasons why they arise is run-out of the tool fixed in the spindle of the machine. The value of the run-out depends on geometrical errors of the tool itself, the tool holder, the spindle, as well as the run-out resulting from inaccurate joining of the above elements. This kind of error can be minimized by the application of a DIHART holder with the possibility of elimination of the tool run-out after fixing. The holder is intended for correcting the tool axis in such a way as to align it with spindle axis.

The application of the above mentioned solutions aiming to reduce the dimensional errors of the machined surfaces involves the necessity of purchasing new tools and holder. The involved costs, however, can be compensated by improvement of the dimensional accuracy of the machined surfaces and, consequently, reduction of the number of defective parts. 


\section{Conclusions}

1. The major factors influencing productivity of manufacturing the water meter body are: high percentage of defective parts (estimated at almost $10 \%$ of the whole year's production), organization of production and the degree of the production personnel training. 2. It has been shown that defective parts result mainly from the process of forging and machining. The problem of defective parts resulting from forging can be partially solved by implementing a new press type MECOL PRESS ME 250. Defective parts resulting from machining can be significantly minimized by introduction of: a stand for supervising the cutting edge condition during machining, application of special tool holders enabling radial tool run-out to be eliminated or purchase of a modern tool set.

3 . In order to increase the productivity the water meter body manufacture, a number of production organization modifications can be performed. Those modifications consists in: the inclusion of a wave transmitter or pager provided for the fork lift operators to accelerate information flow, the provision of spare regenerated tools to the operator and training of production personnel with respects to the identification of the most frequent product defects and correct utilization of the measurement devices.

4. Some of the suggested modifications, e. g. introduction of the stand for supervision of the cutting edge condition during machining, the use of special tool holders compensating the radial run-out of the tool or purchase of modern tool sets will also make possible the improvement of the quality related to the manufacture productivity the quality an manufacture productivity.

5. In the operation of a transfer machine tool, idling as result of failures due to the machine overload take place. The reason of those failures is probably machining overload. In connection with that, investigation to modify the cutting parameters for reduces the machining power should also be performed.

6. The productivity of the water meter body manufacture could also be increased by introducing adequate actions to increase the staff motivation and remuneration of the personnel.

\section{References}

1. J.B. Krolczyk, G.M. Krolczyk, S. Legutko, J. Napiorkowski, S. Hloch, J. Foltys, E. Tama, Teh. Vjesn., 22, (6), 1447-1456 (2015).

2. S. Jun, O. Kochan, Meas. Sci. Rev., 14 (1), 29-34 (2014).

3. J.B. Krolczyk, B. Gapinski, G.M. Krolczyk, I. Samardzic, R.W. Maruda, K. Soucek, S. Legutko, P. Nieslony, Y. Javadi, L. Stas, Teh. Vjesn., 23 (1), 301-306 (2016).

4. S. Wojciechowski, P. Twardowski, M. Pelic, Procedia CIRP, 14, 113-118 (2014).

5. S. Wojciechowski, R.W. Maruda, P. Nieslony, G.M. Krolczyk, Int. J. Mech. Sci., 119, 360-369 (2016).

6. S. Wojciechowski, P. Twardowski, M. Pelic, P.W. Maruda, S. Barrans, S., G.M. Krolczyk, Precis. Eng., 46, 158-165 (2016).

7. A. Glowacz, Meas. Sci. Rev., 15, 167-75 (2015).

8. P. Hreha, A. Radvanska, L. Knapcikova, G. M. Królczyk, S. Legutko, J.B. Królczyk, S. Hloch, P. Monka, Metrol. Meas. Syst., 22 (2), 315-326 (2015).

9. D. Lehocka, J. Klich, J. Foldyna, S. Hloch, J.B. Krolczyk, J. Carach, G.M. Krolczyk, Measurement, 82, 375-383 (2016).

10. R.W. Griffin, Fundamentals of management (Cengage Learning, 2013). 